\title{
Abducens nerve palsy with associated retinal involvement secondary to rickettsia typhi infection
}

\author{
Kaies Abderrahim', Sourour Zina ${ }^{2}$, Molka Khairallah², Hager Ben Amor ${ }^{2}$, Sana Khochtali ${ }^{2}$ and Moncef Khairallah ${ }^{2 *}$
}

\begin{abstract}
Objective: To report a case of abducens nerve palsy with associated retinal involvement due to rickettsia typhi infection.

Material and methods: A single case report documented with multimodal imaging.

Results: A 18-year-old woman with a history of high-grade fever was initially diagnosed with typhoid fever and treated with fluoroquinolone. She presented with a 5-day history of diplopia and headaches. Her best-corrected visual acuity was 20/20 in both eyes. Ocular motility examination showed left lateral gaze restriction. Lancaster test confirmed the presence of left abducens palsy. Fundus examination showed optic disc swelling in both eyes associated with superotemporal retinal hemorrhage and a small retinal infiltrate with retinal hemorrhage in the nasal periphery in the left eye. Magnetic resonance imaging (MRI) of the brain and orbits showed no abnormalities. A diagnosis of rickettsial disease was suspected and the serologic test for Richettsia Typhi was positive. The patient was treated with doxycycline (100 mg every $12 \mathrm{~h}$ ) for 15 days with complete recovery of the left lateral rectus motility and resolution of optic disc swelling, retinal hemorrhages, and retinal infiltrate.

Conclusion: Rickettsial disease should be considered in the differential diagnosis of abducens nerve palsy in any patient with unexplained fever from endemic area. Fundus examination may help establish an early diagnosis and to start an appropriate rickettsial treatment.
\end{abstract}

Keywords: Rickettsiosis, Murine typhus, Fever, Abducens nerve palsy, Retinitis, SD OCT, Case report

\section{Introduction}

Rickettsial infections, are an important, but often underrecognized, cause of undifferentiated febrile illness [1]. Rickettsial agents are classified into three major groups: the spotted fever group, the typhus group, and the scrub typhus group. Murine typhus (MT), also called endemic typhus, is a febrile disease caused by Rickettsia typhi that is often misdiagnosed due to its non-specific presentation [1]. Patients with MT generally present with sudden onset of symptoms including acute sustained fever, severe headache, skin rash, chills, malaise, myalgia and

\footnotetext{
* Correspondence: moncef.khairallah@rns.tn

${ }^{2}$ Department of Ophthalmology, Fattouma Bourguiba University Hospital,

Faculty of Medicine, University of Monastir, 5019 Monastir, Tunisia

Full list of author information is available at the end of the article
}

anorexia [1]. Superficial retinitis, retinal vasculitis, and optic nerve involvement are the most common ocular manifestations of rickettsial disease [2, 3]. Ocular nerve palsies including the three and the six nerves have been rarely described [4-9]. We herein report a case of abducens nerve palsy associated with retinal involvement caused by murine typhus, which was initially misdiagnosed as typhoid fever.

\section{Case report}

A 18-year-old woman presented to our department with a 5-day history of diplopia and headaches. She had developed 15 days earlier a high-grade fever, and had been diagnosed as having typhoid fever and treated with fluoroquinolone. On examination, the

\section{Springer Open}

(๑) The Author(s). 2021 Open Access This article is licensed under a Creative Commons Attribution 4.0 International License, which permits use, sharing, adaptation, distribution and reproduction in any medium or format, as long as you give appropriate credit to the original author(s) and the source, provide a link to the Creative Commons licence, and indicate if changes were made. The images or other third party material in this article are included in the article's Creative Commons licence, unless indicated otherwise in a credit line to the material. If material is not included in the article's Creative Commons licence and your intended use is not permitted by statutory regulation or exceeds the permitted use, you will need to obtain permission directly from the copyright holder. To view a copy of this licence, visit http://creativecommons.org/licenses/by/4.0/. 

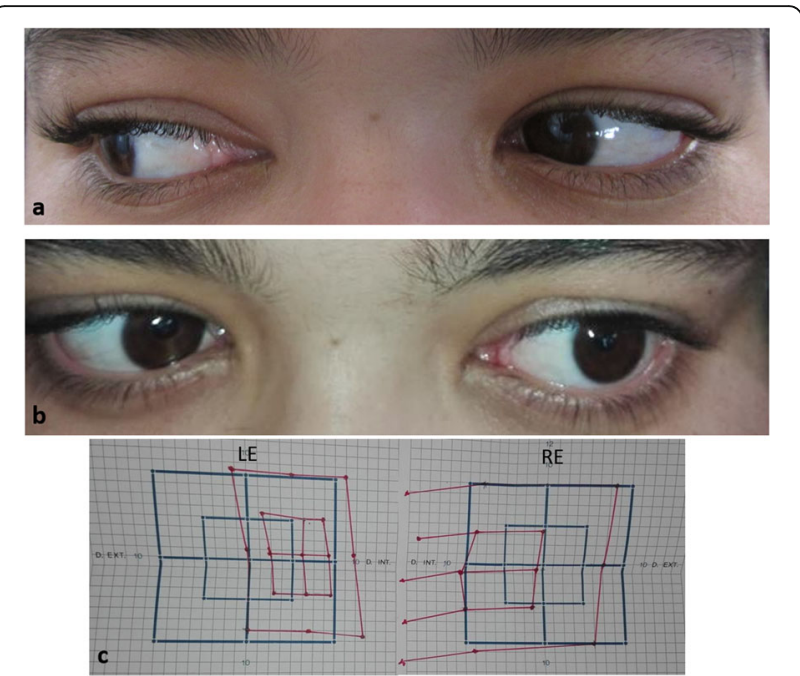

Fig. 1 a, b Photography of the ocular motility examination reveals a left lateral gaze restriction $(\mathbf{b})$. Lancaster test confirms the presence of left abducens palsy (c)

patient's best-corrected visual acuity was 20/20 in both eyes. Ocular motility examination revealed a left lateral gaze restriction (Fig. $1 \mathrm{a}$ and b). Lancaster test confirmed the presence of left abducens palsy (Fig. 1 c). There was no relative afferent pupillary defect. The anterior chamber and the vitreous were quiet in both eyes. Intraocular pressure was normal bilaterally. Fundus examination showed optic disc swelling in both eyes (Fig. 2 a and b). There also were a superotemporal retinal hemorrhage and a small retinal infiltrate with retinal hemorrhage in the nasal periphery in the left eye (Fig. 2 b). Late-phase fundus fluorescein angiograms showed diffuse optic disc leakage in both eyes (Fig. $2 \mathrm{c}$ and d). Macular SD-OCT was unremarkable in both eyes. SD-OCT scan across the retinal infiltrate in the LE showed a focal area of inner retinal thickening and increased reflectivity with posterior shadowing (Fig. 2 e).

Results of physical examination, including neurologic evaluation, were unremarkable. Laboratory work-up showed raised C-reactive protein (CRP), mild thrombocytopenia, and mildly elevated liver enzymes. Magnetic resonance imaging (MRI) of the brain and orbits showed no abnormalities. Rickettsial disease was suspected, and the serologic test for Richettsia Typhi was positive. The patient was treated with doxycycline $(100 \mathrm{mg}$ every $12 \mathrm{~h})$ for 15 days. Symptoms rapidly improved, with complete resolution of diplopia and headaches. Two weeks after initiation of doxycycline therapy, ocular motility examination revealed recovery of the left lateral rectus motility (Fig. 3 a and b). Fundus examination showed the complete resolution of optic disc swelling, retinal hemorrhages, and retinal infiltrate (Fig. $3 \mathrm{c}$ and d). Late-phase fundus fluorescein angiography showed the resolution of optic disc leakage in both eyes (Fig. 3 e and f).

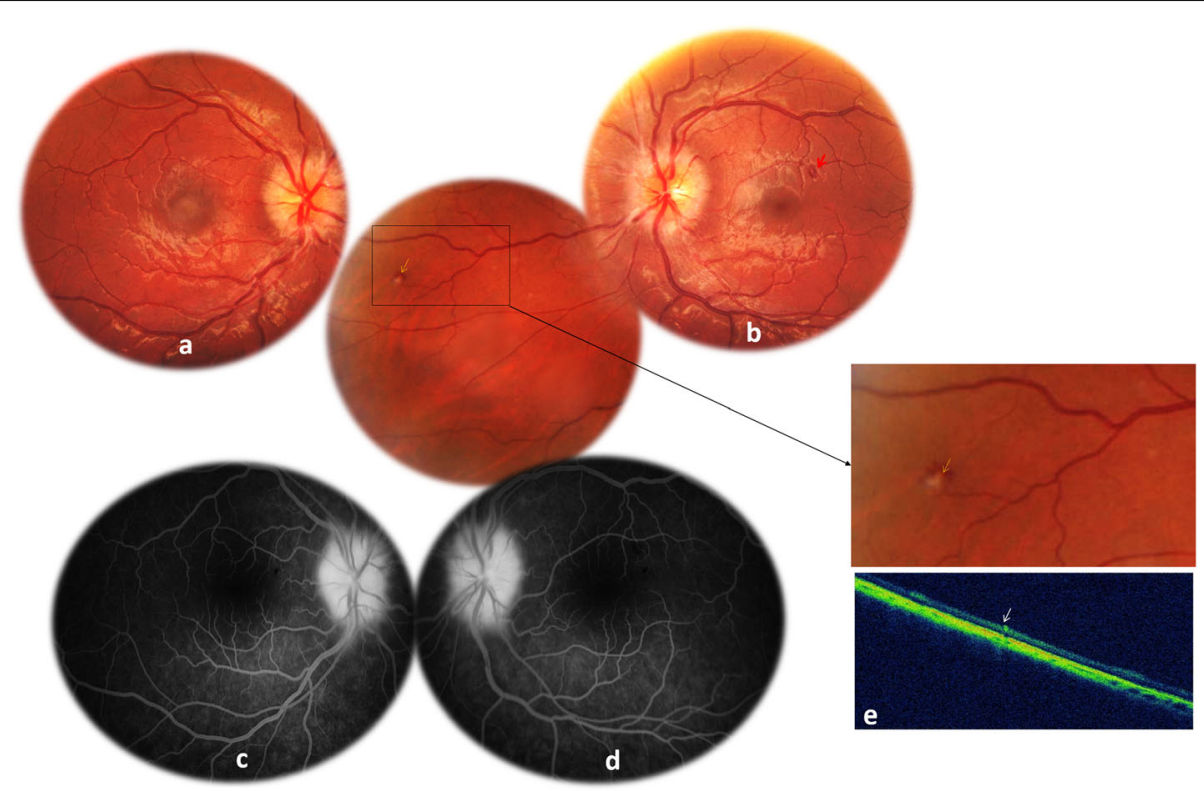

Fig. $2(\mathbf{a}, \mathbf{b})$ Fundus photography at initial presentation showing optic disc swelling in both eyes. Note the presence of a superotemporal retinal hemorrhage (red arrow) and a small retinal infiltrate with retinal hemorrhage in the nasal periphery in the left eye (yellow arrow) more visible in the magnified rectangle (b). c, $\mathbf{d}$ Late-phase fundus fluorescein angiograms showing diffuse optic disc leakage in both eyes. e SD-OCT scan across the retinal infiltrate in the LE showing a focal area of inner retinal thickening and increased reflectivity with posterior shadowing (white arrow) 

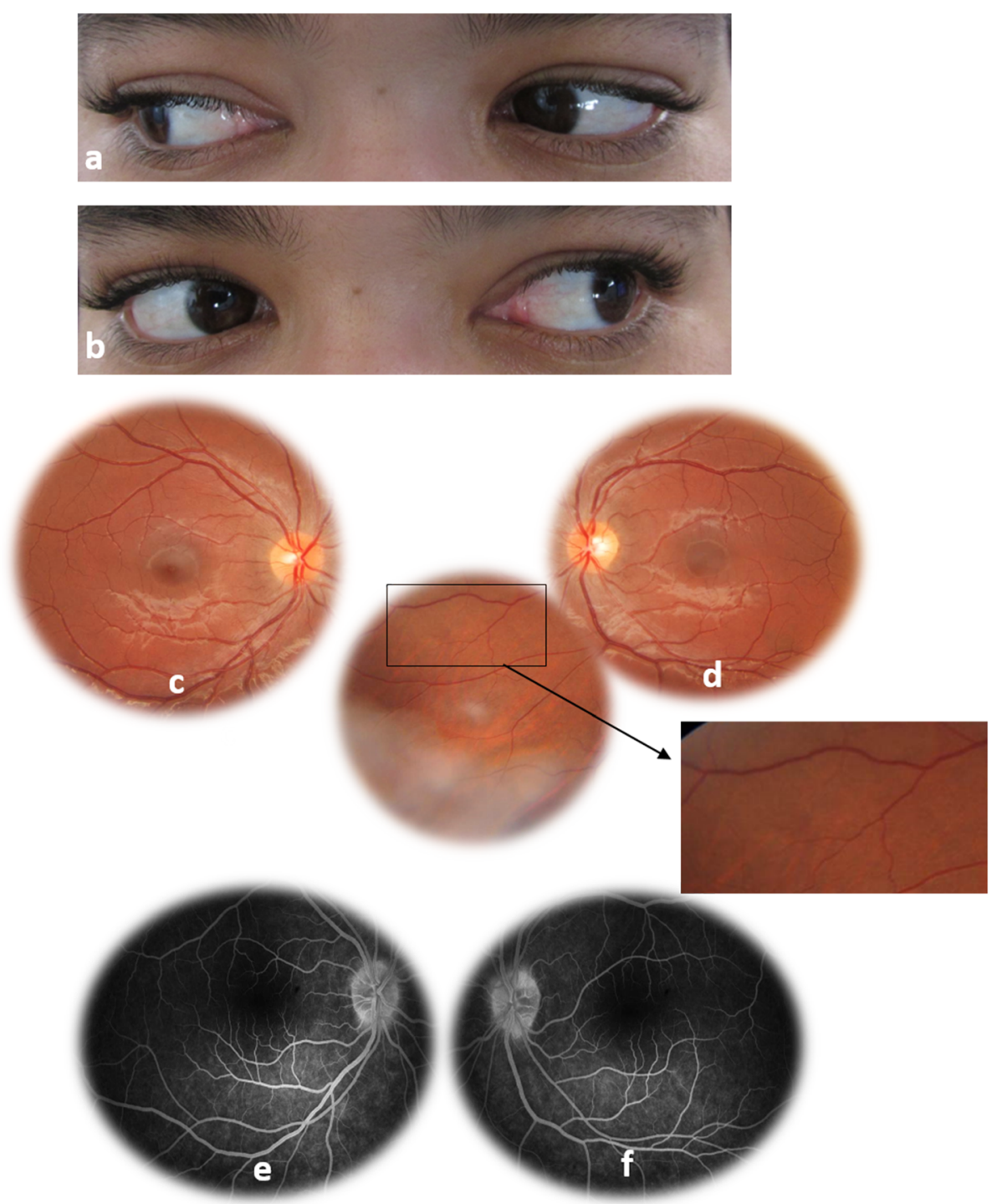

Fig. 3 a, b Photography of the ocular motility examination, two weeks after initiation of doxycycline therapy, reveals recovery of the left lateral rectus motility (b). c, d Fundus photography showing the complete resolution of optic dis swelling, retinal hemorrhages, and retinal infiltrate. $\mathbf{e}$, $\mathbf{f}$ Late-phase fundus fluorescein angiography showing the resolution of optic disc leakage in both eyes

\section{Discussion}

In this report, we describe a case of abducens nerve palsy associated with rickettsial infection. The patient initially presented with high-grade fever and was initially diagnosed as having typhoid fever and treated accordingly. The diagnosis of rickettsial infection was initially missed in the absence of typical skin rash. Fundus examination, showing fairly typical superficial retinal infiltrate, led us to suspect rickettsial disease. The diagnosis was confirmed by the positivity of the serologic test for Richettsia Typhi. The patient received a 15-day course of doxycycline therapy, with subsequent favorable response.
MT is frequently misdiagnosed, being a major cause of fever of unknown origin in numerous geographic regions. The initial clinical presentation of MT develops after an 8- to 16-day incubation period, and includes non-specific clinical manifestations, such as high fever, headaches and an often poorly visible maculopapular rash $[1,2]$. However, this classic triad was found in only one-third of infected patients [1]. Furthermore, the contact with vectors were rarely mentioned by infected patients and flea bites are occasionally found on physical examination [1]. The clinical course of MT is generally benign and self-limited $[1,2]$. Complications are uncommon including pneumonia, renal insufficiency and neurologic involvement $[1,10]$. 
Table 1 Reported cases of murine typhus related abducens nerve palsy

\begin{tabular}{|c|c|c|c|c|c|c|c|c|c|}
\hline Author & Country & $\begin{array}{l}\text { Age } \\
\text { (years) }\end{array}$ & Gender & Fever & Headache & $\begin{array}{l}\text { Skin } \\
\text { rash }\end{array}$ & $\begin{array}{l}\text { Duration of symptoms } \\
\text { before onset of ocular } \\
\text { nerve palsy }\end{array}$ & $\begin{array}{l}\text { Abducens } \\
\text { nerve palsy } \\
\text { laterality }\end{array}$ & Associated complications \\
\hline $\begin{array}{l}\text { Simon NG, } \\
\text { et al. [5] }\end{array}$ & Australia & 20 & Male & + & + & - & 10 & Bilateral & Seizure, Meningoencephalitis \\
\hline $\begin{array}{l}\text { Masalha R, } \\
\text { et al. [6] }\end{array}$ & Israel & 22 & Female & + & + & - & 14 & Right & Mild subacute meningoencephalitis \\
\hline $\begin{array}{l}\text { Hsu CH, et al. } \\
{[8]}\end{array}$ & Indonesia & 31 & Male & + & + & - & 2 & Right & Liver dysfunction \\
\hline $\begin{array}{l}\text { Moy WL, et al. } \\
\text { [7] }\end{array}$ & Singapore & 39 & Male & + & - & - & 9 & Right & Liver dysfunction, Mild meningitis \\
\hline $\begin{array}{l}\text { Moy WL, et al. } \\
{[7]}\end{array}$ & Indonesia & 27 & Female & + & + & - & 4 & Bilateral & $\begin{array}{l}\text { Meningoencephalitis and ventilator } \\
\text { associated pneumonia }\end{array}$ \\
\hline $\begin{array}{l}\text { Lin Ting-Yang, } \\
\text { et al. [9] }\end{array}$ & Taiwan & 39 & Female & + & + & + & 9 & Left & Liver dysfunction \\
\hline Present case & Tunisia & 18 & Female & + & + & - & 10 & Left & Liver dysfunction \\
\hline
\end{tabular}

Besides superficial retinitis, an array of other ocular manifestations has been described in association with rickettsial infection including retinal vasculitis, anterior uveitis, optic disc swelling, optic neuropathy, and Parinaud ocular glandular syndrome [2, 3]. Neurologic complications occur in $2-10 \%$ of patients with MT, and they include aseptic meningitis, meningoencephalitis and rarely, cranial nerve palsy $[1,10]$. There are only a few reported cases of ocular nerve palsy associated with rickettsial disease, mainly involving the third and the sixth nerves [4-9]. Abducens nerve palsy was associated with meningoencephalitis and/or raised intracranial pressure in the majority of reported cases (Table 1) [5-7]. However, isolated abducens nerve palsy without obvious meningoencephalitis was reported only twice (Table 1) [8, 9]. This could result from microvascular infarction involving the cranial nerve, reflecting the marked tropism of rickettsial organisms for the endothelial cells of small vessels. The latter mechanism could explain the development of abducens nerve palsy in our patient, but a raised intracranial pressure could not be excluded. Therefore, bilateral optic disc swelling in our patient might correspond to papillitis or papilledema.

MT should be considered in the differential diagnosis of abducens nerve palsy in any patient with unexplained fever living in or travelling back from a specific endemic area. Ophthalmic examination, showing typical fundus changes, may be helpful to establish an early diagnosis and to start an appropriate rickettsial treatment.

\section{Abbreviations}

CRP: C-reactive protein,; MRI: Magnetic resonance imaging; MT: Murine typhus
Acknowledgments

Ministry of Higher Education and Research of Tunisia.

Authors' contributions

KA and SZ collected data. MK and HBA analyzed and interpreted the patient's data. KA and SZ drafted the manuscript. SK and MK provided critical manuscript revisions. All authors read and approved the final manuscript.

Funding

No funding was received.

\section{Availability of data and materials}

The datasets used and/or analysed during the current study are available from the corresponding author on request.

\section{Declarations}

Ethics approval and consent to participate Not applicable.

Consent for publication

Consent for publication was obtained from the patient.

\section{Competing interests}

The authors declare that they have no competing interests.

\section{Author details}

${ }^{1}$ Department of Ophthalmology, Medenine University Hospital, Faculty of Medicine, University of Sfax, Sfax, Tunisia. ²Department of Ophthalmology, Fattouma Bourguiba University Hospital, Faculty of Medicine, University of Monastir, 5019 Monastir, Tunisia.

Received: 30 January 2021 Accepted: 24 February 2021

Published online: 22 March 2021

\section{References}

1. Tsioutis C, Zafeiri M, Avramopoulos A, Prousali E, Miligkos M, Karageorgos SA (2017) Clinical and laboratory characteristics, epidemiology, and outcomes of murine typhus: a systematic review. Acta Trop 166:16-24

2. Khairallah M, Ben Yahia S, Toumi A, Jelliti B, Loussaief C, Romdhane FB, Messaoud R, Chakroun M (2009) Ocular manifestations associated with murine typhus. Br J Ophthalmol 93(7):938-942

3. Khairallah $M$, Kahloun $R$ (2013) Ocular manifestations of emerging infectious diseases. Curr Opin Ophthalmol 24(6):574-580 
4. Rajadhyaksha A, Phatak S, Nolkha N, Pathan Y, Sonawale A (2013) Rickettsial fever presenting with isolated third nerve palsy. J Assoc Physicians India 61(2):144-145

5. Simon NG, Cremer PD, Graves SR (2011) Murine typhus returns to New South Wales: a case of isolated meningoencephalitis with raised intracranial pressure. Med J Aust 194:652e4

6. Masalha R, Merkin-Zaborsky H, Matar M, Zirkin HJ, Wirguin I, Herishanu YO (1998) Murine typhus presenting as subacute meningoencephalitis. J Neurol 245:665e8

7. Moy WL, Ooi ST (2015) Abducens nerve palsy and meningitis by rickettsia typhi. Am J Trop Med Hyg 92:620e4

8. Hsu CH, Hsieh LP (2014) Murine typhus with presentation of unilateral abducens nerve palsy: a case report. J Intern Med Taiwan 25:36e40

9. Lin T-Y, Lin S-Y, Tun-Chieh C (2018) Murine typhus associated abducens nerve palsy. Kaohsiung J Med Sci 34(9):537-538

10. Silpapojacul K, Ukkachoke C, Krisanapan S, Silpapojacul K (1991) Rickettsial meningitis and encephalitis. Arch Intern Med 151:1753-1757

\section{Publisher's Note}

Springer Nature remains neutral with regard to jurisdictional claims in published maps and institutional affiliations.

\section{Submit your manuscript to a SpringerOpen ${ }^{\odot}$ journal and benefit from:}

- Convenient online submission

- Rigorous peer review

- Open access: articles freely available online

- High visibility within the field

- Retaining the copyright to your article

Submit your next manuscript at $\boldsymbol{\wedge}$ springeropen.com 